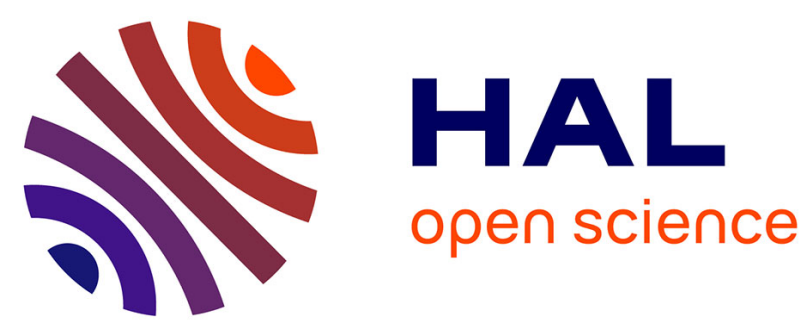

\title{
Contrast-Matched Isotropic Bicelles: A Versatile Tool to Specifically Probe the Solution Structure of Peripheral Membrane Proteins Using SANS
}

Raphael dos Santos Morais, Olivier Delalande, Javier Perez, Liza Mouret, Arnaud Bondon, Anne Martel, Marie-Sousai Appavou, Elisabeth Le Rumeur, Jean-François Hubert, Sophie Combet

\section{To cite this version:}

Raphael dos Santos Morais, Olivier Delalande, Javier Perez, Liza Mouret, Arnaud Bondon, et al.. Contrast-Matched Isotropic Bicelles: A Versatile Tool to Specifically Probe the Solution Structure of Peripheral Membrane Proteins Using SANS. Langmuir, 2017, 33 (26), pp.6572-6580. 10.1021/acs.langmuir.7b01369 . hal-01560241

\section{HAL Id: hal-01560241}

\section{https://hal-univ-rennes1.archives-ouvertes.fr/hal-01560241}

Submitted on 13 Sep 2017

HAL is a multi-disciplinary open access archive for the deposit and dissemination of scientific research documents, whether they are published or not. The documents may come from teaching and research institutions in France or abroad, or from public or private research centers.
L'archive ouverte pluridisciplinaire HAL, est destinée au dépôt et à la diffusion de documents scientifiques de niveau recherche, publiés ou non, émanant des établissements d'enseignement et de recherche français ou étrangers, des laboratoires publics ou privés. 


\title{
Contrast-matched isotropic bicelles: a versatile tool
}

\section{to specifically probe the solution structure of peripheral membrane proteins using SANS.}

Raphael Dos Santos Morais ${ }^{1,2,3,4}$, Olivier Delalande ${ }^{1,2}$, Javier Pérez ${ }^{4}$, Liza Mouret ${ }^{5}$, Arnaud Bondon $^{5}$, Anne Martel ${ }^{6}$, Marie-Sousai Appavou', Elisabeth Le Rumeur ${ }^{1,2}$, Jean-François Hubert ${ }^{1,2}$, and Sophie Combet ${ }^{3, *}$.

${ }^{1}$ Université de Rennes 1, F-35043 Rennes, France. ${ }^{2}$ CNRS UMR 6290, Institut de Génétique et Développement de Rennes, F-35043 Rennes, France. ${ }^{3}$ Laboratoire Léon-Brillouin, UMR 12 CEA-CNRS, Université Paris-Saclay, CEA-Saclay, Gif-sur-Yvette CEDEX F-91191, France. ${ }^{4}$ SWING Beamline, Synchrotron SOLEIL, L'Orme des Merisiers, BP48, Saint-Aubin, Gif-surYvette, F-91192, France. ${ }^{5}$ CNRS 6226, Institut des Sciences Chimiques de Rennes, PRISM, F350043 Rennes, France. ${ }^{6}$ Institut Laue-Langevin, F-38042 Grenoble, France. ${ }^{7}$ Jülich Centre for Neutron Science (JCNS) at Heinz Maier-Leibnitz Zentrum (MLZ), Forschungszentrum Jülich GmbH, Lichtenbergstr. 1, D-85748 Garching, Germany.

\begin{abstract}
Obtaining structural information on integral or peripheral membrane proteins is currently arduous due to the difficulty of their solubilization, purification, and crystallization (for X-ray crystallography (XRC) application). To overcome this challenge, bicelles are known to be a
\end{abstract}


versatile tool for high-resolution structure determination, especially when using solution and/or solid state nuclear magnetic resonance (NMR) and, to a lesser extent, XRC. For proteins not compatible with these high-resolution methods, small-angle X-ray and neutron scattering (SAXS and SANS, respectively) are powerful alternatives to obtain structural information directly in solution. In particular, the SANS-based approach is a unique technique to obtain low-resolution structures of proteins in interactions with partners by contrast-matching the signal coming from the latter. In the present study, isotropic bicelles are used as a membrane mimic model for SANS-based structural studies of bound peripheral membrane proteins. We emphasize that the SANS signal coming from the deuterated isotropic bicelles can be contrast-matched in $100 \%$ $\mathrm{D}_{2} \mathrm{O}$-based buffer, allowing us to separately and specifically focus on the signal coming from the protein in interaction with membrane lipids. We applied this method to the DYS-R11-15 protein, a fragment of the central domain of human dystrophin known to interact with lipids, and we were able to recover the signal from the protein alone. This approach gives rise to new perspectives to determine the solution structure of peripheral membrane proteins interacting with lipid membranes and might be extended to integral membrane proteins.

\section{INTRODUCTION}

While approximately $26 \%$ of the human proteome is predicted to be composed of membrane proteins ${ }^{1}$, the structures of only 685 unique membrane proteins are available ${ }^{2}$. This highlights the difficulty in handling membrane proteins during their solubilization, purification and crystallization ${ }^{3}$. For even more recalcitrant membrane proteins incompatible with highresolution methods (nuclear magnetic resonance (NMR) and X-ray crystallography (XRC)), small-angle X-ray and neutron scattering (SAXS and SANS, respectively) are good alternative 
approaches to obtain the structural information of a protein not only alone in solution but also in interaction with its partner(s) ${ }^{4,5}$. In the SANS-based approach, the contrast matching $(\mathrm{CM})$ technique allows the signal coming from one component to be specifically probed by hiding the signal coming from other partners in a multicomponent system. This is achieved by adjusting the deuteration level of the components in an appropriate $\mathrm{H}_{2} \mathrm{O} / \mathrm{D}_{2} \mathrm{O}$ ratio. The $\mathrm{CM}$ technique has been successfully applied to the determination of the structure of one component in proteinprotein and protein-DNA complexes ${ }^{6}$. Protein-lipid complexes have also been successfully investigated in the same way with different membrane mimic environments ${ }^{7}$. In an elegant study, Gabel et al. ${ }^{8}$ investigated the conformation of the $\beta$-barrel transporter FhaC surrounded by a $\beta$ octyl glucoside corona by coupling SANS and molecular modeling, obtaining a conformation of the protein similar to that obtained by XRC. Although detergent micelles are considered suitable for maintaining the tridimensional structure of membrane proteins, some authors ${ }^{9}$ proposed that the loss of activity evidenced for some membrane proteins could be inherent to the lack of their internal dynamics in detergent micelles compared with bilayered membrane mimics. Indeed, membrane models other than micelles are available and the interest for reconstructing a biological native lipid environment for membrane proteins is growing ${ }^{10-12}$. Among them are the classical liposome model but also relatively more recent ones, such as nanodiscs and bicelles, which can be good alternatives ${ }^{10-12}$. However, all of these membrane mimics have their advantages and drawbacks ${ }^{10-12}$.

Nanodiscs are phospholipid bilayers surrounded by either a membrane scaffolding protein $(\mathrm{MSP})^{13}$ or a stryrene maleic acid (SMA) copolymer ${ }^{14}$. By using these membrane mimics, Maric et $a l .{ }^{15}$ proposed an interesting method to use SANS to analyze integral membrane proteins incorporated into contrast-matched nanodiscs. In the case of peripheral membrane proteins, it is 
essential to maintain a phosphatidylcholine head all over the membrane mimic to avoid nonspecific interactions that could happen between the scaffold of the nanodisc and the protein of interest. This can be achieved by handling peripheral proteins with fully phospholipid-based bicelles. Moreover, the size of bicelles can be easily adjusted and does not require the use of several MSP truncated forms ${ }^{16,17}$. Last but not least, in addition to the intrinsic highly curved rim region, few curvature-inducing molecules can be incorporated into bicelles in order to modify the planarity of the bilayer $\operatorname{part}^{18}$. These properties reinforce the suitability of the bicelle model for mimicking membrane bending, known to be essential for various biological processes ${ }^{19}$. These three points constitute the most important advantages of phospholipid-based bicelles compared to nanodiscs.

Bicelle aggregates are made of long-chain phospholipids arranged in a bilayer surrounded by a torus of short-chain phospholipids or detergents. Pioneering studies describing such objects were performed on lecithin/bile-salt or analogues ${ }^{20,21}$ and dipalmitoylphosphatidylcholine/diheptanoylphosphatidylcholine (DPPC/DH $\mathrm{DC}_{7}$ ) solution ${ }^{22,23}$. To better mimic the membrane bilayer, unsaturated phospholipids, cholesterol ${ }^{24,25}$, or anionic phospholipids ${ }^{26}$ were successfully incorporated into the bilayer part. Recently, bicelles were even constructed from native Escherichia coli lipids $^{27}$, but the currently best-described system is made of dimyristoylphosphatidylcholine/dihexanoylphosphatidylcholine (DMPC/DHPC) since its first characterization by solid-state $\mathrm{NMR}^{28}$. The molar ratio (DMPC/DHPC), denoted " $q$ ", of the two components forming the bicelles is the major parameter governing the bicelle size. This parameter can be easily adjusted according to the desired final size for a required application. Its value distinguishes two types of bicelles. The larger ones $(q \geq 2.5)$ are able to align in a magnetic field above the gel-to-fluid phase transition temperature $\left(T_{m}\right)$. They are commonly used in solid 
state $\mathrm{NMR}^{29,30}$ and increasingly in $\mathrm{XRC}^{31-33}$, while existing as perforated lamella rather than disks in these conditions ${ }^{34}$. The other type, small isotropic bicelles $(q<2.5)$, are commonly used in solution $\mathrm{NMR}^{29,30}$. Despite their versatility, the morphology and the size of the bicelles are reported to be highly sensitive to $q$, temperature, and dilution ${ }^{35,36}$. DMPC/DHPC bicelles were thoroughly investigated with cryo-electronic microscopy, dynamic light scattering (DLS) and $\mathrm{NMR}^{35-39}$, but only a few studies were performed with $\mathrm{SANS}^{40-44}$. The study by Luchette $e$ al. ${ }^{40}$ is, to our knowledge, the only one devoted to SANS characterization of hydrogenated DMPC/DHPC isotropic bicelles.

In the present work, we analyzed both hydrogenated and deuterated isotropic bicelles (hbicelles and d-bicelles, respectively) in the range of $1 \leq q \leq 1.3$. We demonstrate that the dbicelles can be contrast-matched in $100 \% \mathrm{D}_{2} \mathrm{O}$-buffer regardless of their morphology and temperature. We applied this method to a protein fragment of the dystrophin central domain, DYS R11-15, known to interact with the lipid membranes ${ }^{45-47}$. We highlight that one can specifically probe the signal of a peripheral membrane protein bound to bicelles. In addition, we show that SANS analysis can be properly achieved on bicelles previously submitted to highpressure size exclusion chromatography.

\section{MATERIALS AND METHODS}

\section{Materials}

1,2-dimyristoyl-sn-glycero-3-phosphocholine ～(DMPC), 1,2-dihexanoyl-sn-glycero-3phosphocholine (DHPC), 1,2-dimyristoyl-d54-sn-glycero-3-phosphocholine-1,1,2,2-d4-N,N,Ntrimethyl-d9 (DMPC-d67), and 1,2-dihexanoyl-d22-sn-glycero-3-phosphocholine-1,1,2,2-d4- 
N,N,N-trimethyl-d9 (DHPC-d35), conditioned in chloroform, are from Avanti Polar Lipids and were used without any further purification. $\mathrm{D}_{2} \mathrm{O}$, Tris-d11, and EDTA-d16 are from Eurisotop.

\section{Bicelle preparation}

A chloroform solution containing the appropriate amounts of DMPC/DHPC or DMPC$\mathrm{d} 67 / \mathrm{DHPC}-\mathrm{d} 35$, to obtain a ratio $(\mathrm{mol} / \mathrm{mol}) q=1$, was dried overnight under vacuum. The lipid mixture was then rehydrated in d-TNE buffer solution $(20 \mathrm{mM}$ Tris-d11, $150 \mathrm{mM} \mathrm{NaCl}$, and $0.1 \mathrm{mM}$ EDTA-d16, $\mathrm{pD} 7.5$ ) or TNE buffer to reach a total lipid concentration of at least $200 \mathrm{mM}$. Once rehydrated, the solution was frozen $\left(10 \mathrm{~s}\right.$ in liquid $\left.\mathrm{N}_{2}\right)$, thawed $\left(10 \mathrm{~min}\right.$ at $\left.40^{\circ} \mathrm{C}\right)$, vigorously shaken with a vortex (1 min), and then centrifuged (1.5 min, 6,000 rpm, MiniSpin, Eppendorf). This procedure was repeated two more times to homogenize the solution. Stock solutions were diluted in d-TNE or TNE based on needs.

\section{The ideal bicelle model (IBM)}

Isotropic bicelles are considered to be disk-shaped objects made of long-chain phospholipids forming a bilayer, surrounded by short-chain phospholipids located at the rim (Figure 1A). The molar ratio of the two phospholipids, denoted " $q$ " (not to be confused with " $Q$ " used here for the scattering vector in SANS and DLS experiments), is the main parameter governing the size of the bicelles. The effective molar ratio is denoted " $q_{\text {eff }}$ ",35,37 when the proportion of free DHPC is considered, and is defined by

$$
q_{\text {eff }}=\frac{[\mathrm{DMPC}]}{[\mathrm{DHPC}]_{\text {total }}-[\mathrm{DHPC}]_{\text {free }}}
$$

$\mathrm{Eq} 1$

Several IBMs are proposed to correlate $q_{\text {eff }}$ to the radius of the bicelle. These models are based either on head group area ${ }^{30,43}$ or on phospholipid volume ${ }^{49}$. We consider the latter model to be 
the most reliable one since the molecular volumes of phospholipids are barely different below and above $T_{m}{ }^{50,51}$ and the equation does not depend on the thickness of the bilayer. The radius of IBM can be expressed as ${ }^{38,49}$ (Figure 1)

$$
R=\mathrm{r}_{\perp}+\frac{\mathrm{r}_{\perp} q_{e f f}}{4 \Lambda}\left[\pi+\left(\pi^{2}+\frac{32 \Lambda}{3 q_{e f f}}\right)^{1 / 2}\right]
$$

where $R$ is the radius of the bicelle, $r \perp$ is the thickness of the rim $(11 \AA$, the length of a DHPC molecule), $\Lambda$ is the volume ratio of DHPC to DMPC (0.61), and $t$ is the thickness of the bilayer (assumed to be $40 \AA)^{49}$. According to Small ${ }^{52}$, the volumes of DMPC and DHPC are 1090 and $660 \AA^{3}$, respectively.

${ }^{31}$ P NMR spectroscopy

${ }^{31} \mathrm{P}$ NMR spectra were recorded on a Bruker spectrometer Avance 500 equipped with a 5-mm BBO probe operating at $202.46 \mathrm{MHz}$. Spectra of $10 \mathrm{kHz}$ spectral width and $32 \mathrm{~K}$ data points were acquired with proton decoupling using 128 scans, a $30^{\circ}$ flip angle, and a 0.5 s relaxation delay. The data were processed with the TopSpin3.2 software (Bruker). Before applying the Fourier transform, free induction decays were treated with an exponential broadening of $2 \mathrm{~Hz}$. $85 \% \mathrm{H}_{3} \mathrm{PO}_{4}$ was used as an external standard for the ${ }^{31} \mathrm{P}$ chemical shift.

\section{Dynamic light scattering}

The monodispersity and the hydrodynamic radius $\left(R_{h}\right)$ of the bicelles were estimated by DLS using a Zetasizer instrument (Nano ZS, Malvern Instruments). Measurements were done in a temperature range from 15 to $37^{\circ} \mathrm{C}$ in low volume Hellma cells $(100 \mu \mathrm{L})$. The data were processed with the Zetasizer software v7.11 with default parameters and characterized by the size distribution by intensity. The decay rate, $\Gamma$, of the autocorrelation function is linked to the 
diffusion coefficient $D$ by $\Gamma=D Q^{2}$, where $Q$, the momentum transfer, is defined as $Q=$ $\frac{4 \pi n \sin \theta}{\lambda}$, where $n$ is the refractive index of the medium, $\lambda$ the wavelength of the laser, and $2 \theta$ the scattering angle. $R_{h}$ is determined with the Stokes-Einstein equation: $R_{h}=\frac{k_{B} T}{6 \pi \eta D}$, where $k_{B}$ is the Boltzmann constant, $T$ the temperature, and $\eta$ the viscosity of the medium. Data were processed using the viscosity of heavy water according to the temperature ${ }^{53}$.

\section{DYS R11-15 protein purification}

The DYS R11-15 protein was expressed and purified as previously described ${ }^{45}$. The purity was assessed by SDS-PAGE (Figure S3A) and Coomassie blue staining (InstantBlue, Expedeon). TNE to d-TNE buffer exchange was performed with Amicon Ultra-15 (MWCO 10 kDa). Exactly the same buffer was used for both bicelle rehydration and SANS acquisition to ensure a perfect buffer subtraction in all cases.

\section{Intrinsic tryptophan fluorescence}

Fluorescence measurements were obtained on a Fluorolog spectrofluorometer (Jobin-Yvon). Tryptophan fluorescence emission spectra were recorded at $20^{\circ} \mathrm{C}$ in low volume quartz cuvettes $(120 \mu \mathrm{L})$ between 310 and $420 \mathrm{~nm}$ using an excitation wavelength of $295 \mathrm{~nm}$ (bandwidth $2 \mathrm{~nm}$ ) in TNE buffer. The protein concentration was $10 \mu \mathrm{M}$ and the lipid concentration was $50 \mathrm{mM}$.

\section{Chromatographic co-elution}

Data were collected using a Bio SEC-5 $500 \AA$ column $(5 \mu \mathrm{m}, 4.6 \mathrm{~mm}$ x $300 \mathrm{~mm}$, Agilent) mounted on an ÄKTA Explorer HPLC system (GE Healthcare). The column was equilibrated with TNE buffer supplemented with $6 \mathrm{mM}$ of DHPC to avoid bicelle deformation under diluted concentration. A sample volume of $50 \mu \mathrm{L}$ was loaded onto the column. For DYS R11-15 alone, 
the protein concentration was $60 \mu \mathrm{M}$ and for the bicelles alone, the lipid concentration was $50 \mathrm{mM}$. For the lipid-protein complex, the concentrations were $94 \mu \mathrm{M}$ for the protein and $50 \mathrm{mM}$ for the lipids. The flow rate was $0.2 \mathrm{~mL} / \mathrm{min}$.

\section{Small angle neutron scattering experiments}

SANS data were recorded on either the PACE ${ }^{54}$ (LLB, Saclay), KWS1 ${ }^{55,56}$ (MLZ, Garching), or D22 $2^{57}$ (ILL, Grenoble) SANS instruments. According to the predicted size of the bicelles, two or three sample-to-detector distances were used with a wavelength varying from 4.7 to $6 \AA$, to cover a $Q$-range from 0.005 to $0.5 \AA^{-1}$ for the largest one, where $Q=\frac{4 \pi \sin \theta}{\lambda}$ is the momentum transfer, $\lambda$ is the wavelength, and $2 \theta$ is the scattering angle. All measurements were done in $1 \mathrm{~mm}$ Hellma Suprasil quartz (QS) cells.

\section{High-pressure size exclusion chromatography-SANS}

High-pressure size exclusion chromatography (HPSEC)-SANS data were acquired on the D22 instrument (ILL, Grenoble) with the single configuration of $8 \mathrm{~m}$ collimation and sample-detector distance, at $\lambda=6 \AA \pm 10 \%$, covering a $Q$-range from 0.008 to $0.17 \AA^{-1}$. The sample environment was described elsewhere ${ }^{58}$. Data were collected using a Bio SEC-5 $500 \AA$ column $(5 \mu \mathrm{m}, 4.6 \mathrm{~mm}$ x $300 \mathrm{~mm}$, Agilent) equilibrated with the d-TNE buffer supplemented with $6 \mathrm{mM}$ of. A volume of $100 \mu \mathrm{L}$ of bicelle solution at $50 \mathrm{mM}$ was loaded onto the column. The flow rate was 0.2 $\mathrm{mL} / \mathrm{min}$. The SANS signal of the buffer was collected in-line before the void volume, allowing a perfect subtraction to be done.

SANS data analysis

SANS data were analyzed with the ATSAS suite ${ }^{59}$, following its guidelines unless otherwise 
indicated. The PRIMUS software ${ }^{60}$ was used to estimate the dimensions of the bicelles. At small $Q$ values, the Guinier approximation (for $Q R_{g}<1.3$ ) was used to determine the forward intensity $I(0)$ and the radius of gyration $R_{g}$ and is defined by ${ }^{61}$

$$
I(Q)=I(0) \exp \left(-\frac{Q^{2} R_{g}^{2}}{3}\right)
$$

At intermediate $Q$ values, for a disk-shaped object, the Guinier approximation allows the crosssectional radius of gyration $R_{t}$ to be approximated and is defined by ${ }^{61}$

$$
I(Q)=\frac{I(0)}{Q^{2}} \exp \left(-Q^{2} R_{t}^{2}\right)
$$

Eq 4

For a disk-shaped object of homogenous SLD contrast, $R_{t}$ and $R_{g}$ are related to the thickness $t$ and the radius $R$ of the disk by ${ }^{61}$

$$
R_{t}^{2}=\frac{t^{2}}{12} \text { and } R_{g}^{2}=\frac{R^{2}}{2}+\frac{t^{2}}{12}
$$

Eq 5 and 6

\section{SANS data fitting parameters}

For our calculations, we used the volumes of DMPC and DHPC from Small ${ }^{52}$ (1090 and $660 \AA^{3}$ respectively). The volume of the tail, excluding the carbons belonging to the carbonyl functions, was estimated using the empirical rule of Tanford ${ }^{62}$. Then, the volume of the lipid head was obtained simply by subtracting the volume of the tail from the total volume. The densities were estimated from the molecular formula and the volumes. The scattering length density (SLD) was calculated using the NIST website ${ }^{63}$. A summary table is available (Table S1). Data were fitted with the "core-shell cylinder" model ${ }^{64}$ (Figure 1B), described in the supporting information (Eq. $\mathrm{S} 1, \mathrm{~S} 2$, and S3). We fixed the following parameters to fit SANS data: the thicknesses of the shell 
$\left(t_{s}\right)$ and of the core $\left(t_{c}\right)$ were 6 and $28 \AA$, respectively. The SLD of the solvent was $6.3410^{-6} \AA^{-2}$. The thickness of the core had to be released in order to fit the data of d-bicelles at $37^{\circ} \mathrm{C}$. All data fitting procedures for form factor determination were done using the SASview v3.1.0 software $^{65}$.

\section{RESULTS AND DISCUSSION}

\section{Characterization of the h-bicelles}

Beaugrand et al. ${ }^{37}$, in analogy with the critical micellar concentration for the micelles, introduced the critical bicellar concentration $(\mathrm{CBC})$, which corresponds to the concentration of free DHPC in a bicelle solution ${ }^{35}$. They also defined the concentration boundaries to maintain the bicelle size for a defined $q$ ratio. Mineev et $a l .{ }^{38}$ recently proposed to determine the concentration of free DHPC by NMR diffusion, as previously done by Chou et al. ${ }^{66}$, and to dilute the sample in a buffer containing the same DHPC concentration in order to maintain the expected $q$ ratio and thus the bicelle size under diluted conditions. We decided to take advantage of the free DHPC in solution to obtain bicelles with a molar ratio, $q_{\text {eff, }}$, ranging from 1 to 1.3 by assuming a CBC value of $6 \mathrm{mM}$ throughout this $\mathrm{study}^{37}$. This value is known to be almost constant in our $q_{\text {eff }}$ range and in a wide range of temperatures ${ }^{37}$. Note that all concentrations hereafter indicate the total lipid concentration where the $\mathrm{CBC}$ is not subtracted. The $q_{\text {eff }}$-range $\left(1 \leq q_{\text {eff }} \leq 1.3\right)$ was chosen since the morphology of small isotropic bicelles $\left(q_{\text {eff }}<1\right)$ is still largely debated. Below this threshold, the objects would be present as mixed-micelles ${ }^{37}$ or as real disk-shaped objects $^{38,39}$. First, we checked the specific organization in bicelles and the correct molar ratio of our preparation by analyzing a concentrated sample $(200 \mathrm{mM}, q=1)$ by ${ }^{31} \mathrm{P}$ NMR (Figure $\left.2 \mathrm{~A}\right)$. The spectrum is characteristic of isotropic bicelles with a narrow peak and a broader one attributed to DHPC and DMPC, respectively ${ }^{28}$. The molar ratio of 1 , calculated from the 
integrals of the two peaks, is in line with the $q=1$ expected value. Since the morphology and the size of the bicelles may be affected by $q_{e f f}^{36,67}$, less concentrated samples diluted with the d-TNE buffer, at 100,75 , and $50 \mathrm{mM}$ of lipids (Figure $2 \mathrm{~B}$ ), were analyzed by SANS at $20^{\circ} \mathrm{C}$, below the gel-to-fluid phase transition temperature of DMPC $\left(24^{\circ} \mathrm{C}\right)^{68}$. For these three concentrations, a plateau is reached, which is characteristic of objects with a finite size. The radii of gyration $\left(R_{g}\right)$ obtained for the three concentrations are $25.5 \pm 0.2,28.0 \pm 0.3$, and $33.5 \pm 0.4 \AA$. As expected, the bicelles size increases with $q_{\text {eff }}$ (Figure $2 \mathrm{~B}$ ). On the other hand, the intermediate radius of gyration $\left(R_{t}\right)$ remains constant at $12.0 \pm 0.1 \AA$. For a disk-shaped object of homogeneous SLD contrast, the $R_{g}$ values correspond to geometric radii of approximately 32,36 , and $44 \AA$, while the $R_{t}$ value corresponds to a thickness (t) of approximately $41.5 \AA$, in line with the dimension of a DMPC bilayer in gel phase ${ }^{69}$. We also analyzed the stock solution $(265 \mathrm{mM})$ and observed a structure peak (Figure S1) associated with an interparticle spacing previously observed by Luchette et $a l^{40}$ in similar conditions. This peak is no longer observable for the more diluted samples, down to $50 \mathrm{mM}$. More diluted samples were also analyzed (25 and $10 \mathrm{mM}$ ) and, as expected, the samples are no longer disk-shaped objects at these concentrations since $q_{\text {eff }}$ increases strongly (data not shown). Finally, to confirm that the bicelles at $50 \mathrm{mM}$ are effectively discoidal objects, data obtained at this concentration were fitted with the "core-shell cylinder" form factor model ${ }^{64}$. This two-step SLD cylinder model allows the tails and the heads of the phospholipids to be distinguished. We assume that the SLD for DMPC and DHPC heads are identical since they have the same chemical function. This affirmation might not be absolutely true because differences in the level of hydration between the bilayer and the rim could modify the SLD. Indeed, the areas occupied by the heads of both phospholipids are known to be different in the case of a DMPC bilayer in gel $\left(47 \AA^{2}\right)^{69}$ or in fluid phase $\left(60 \AA^{2}\right)^{70}$ or for DHPC 
micelles $\left(100 \AA^{2}\right)^{71}$. We also fixed the thickness of the core and of the shell to 28 and $6 \AA$, respectively, to reduce the number of free parameters during the fitting procedure. Despite these approximations, good fits were obtained (Figure 2B) using this simplified model for h-bicelles, giving overall dimensions of $40 \AA$ for the thickness $(t)$ and $42 \AA$ for the total radius $(R)$. These results are in line with the first Guinier approximations and the IBM proposed by Tryba et al. ${ }^{49}$. Altogether, these data show that the experimental conditions used for the h-bicelles led to diskshaped objects. Therefore, the same experimental conditions were used in the following experiments with the d-bicelles.

\section{Deuterated bicelles are contrast-matched in $100 \% \mathrm{D}_{2} \mathrm{O}$ buffer}

We used almost fully deuterated DMPC and DHPC lipids, commercially available, to form the dbicelles (five hydrogen atoms remain near the glycerol group). The d-bicelles at $50 \mathrm{mM}$ were analyzed at three contrasts: 42,70 , and $100 \% \mathrm{D}_{2} \mathrm{O} / \mathrm{H}_{2} \mathrm{O}$ ratios (Figure 3). First, to probe the expected disk-shaped morphology, data from the d-bicelles at $42 \% \mathrm{D}_{2} \mathrm{O}$ (corresponding to the classical contrast-matching point of hydrogenated proteins) was used for further analysis after incoherent subtraction (Figure 3). We used the Guinier approximation to estimate the overall dimensions of these disk-shaped objects. We obtained $R_{g}$ and $R_{t}$ values of $31.5 \pm 0.1$ and 12.5 $\pm 0.1 \AA$, respectively, corresponding to a radius $(R)$ of approximately $41 \AA$ and a thickness $(t)$ of $43 \AA$. Then, the data for d-bicelles were fitted with the same model and assumptions as for the hbicelles. A good fit was obtained (Figure 3) by using the "core-shell cylinder" model, giving overall dimensions of $40 \AA$ for the thickness $(t)$ and $44 \AA$ for the total radius $(R)$, in-line with the Guinier approximation and the theoretical IBM. 
According to our calculations, the SLD for DMPC-d67 and DHPC-d35 are 6.65 and $6.2010^{-6} \AA^{-}$

${ }^{2}$, respectively, and are close to the SLD of $100 \% \mathrm{D}_{2} \mathrm{O}$-based buffer of $6.3410^{-6} \AA^{-2}$. Therefore, considering SANS resolution, d-bicelles should be nearly contrast-matched in 100\% d-TNE buffer. As expected, d-bicelles at $100 \% \mathrm{D}_{2} \mathrm{O}$ are virtually contrast-matched in SANS, with a small residual signal at small angles, which is negligible (Figure 3, insert). The signal of the dbicelles in $70 \% \mathrm{D}_{2} \mathrm{O}$ is more than 20 -fold higher and almost two orders of magnitude higher in $42 \%$ than in $100 \% \mathrm{D}_{2} \mathrm{O}$. By plotting the square-root of SANS intensity as a function of the percentage of $\mathrm{D}_{2} \mathrm{O}$, we obtained for the data above a match-point of $104 \% \mathrm{D}_{2} \mathrm{O}$ (Figure $\mathrm{S} 1 \mathrm{~A}$ ). To compare with our experimental data, theoretical curves were generated for a $Q$-range from 2.5.10 $0^{-2}$ to $0.5 \AA^{-1}$ with the SASview software, using the above parameters obtained for the dataset at $42 \% \mathrm{D}_{2} \mathrm{O}$, in $0,20,42,70,90$, and $100 \% \mathrm{D}_{2} \mathrm{O}$ (Figure $\mathrm{S} 1 \mathrm{C}$ ). The theoretical matchpoint of the d-bicelles was determined with the same plot as above (Figure S1B) and is around $99 \% \mathrm{D}_{2} \mathrm{O}$, in-line with the experimental determination. Considering experimental and theoretical data, $100 \% \mathrm{D}_{2} \mathrm{O}$ is assumed to be a reliable match-point value We concluded that the d-bicelles are virtually contrast-matched in $100 \%$ d-TNE buffer, whose salt concentration and $\mathrm{pH}$ are relevant for biological applications ${ }^{46}$. These first analyses were performed at $20^{\circ} \mathrm{C}$. The gel-tofluid transition temperatures of DMPC and DMPC-d54 are 24 and $20^{\circ} \mathrm{C}^{72,73}$, respectively, and the acute control of the bicelle size and morphology is a key parameter in these studies. Therefore, we decided to explore structural modification of the isotropic bicelles depending on temperature since this was previously achieved in other systems ${ }^{34,36}$.

\section{Thermal effects on bicelle morphology and contrast-matching}

To ensure that the studied membrane mimic objects were disk-shaped, we performed a screening of temperature effects on both the h- and d-bicelles using DLS. Measurements were performed 
from 15 to $37^{\circ} \mathrm{C}$ (Figure 4A). The figure highlights the hydrodynamic radius $\left(R_{h}\right)$ variation of the bicelles according to temperature. For the h-bicelles, $R_{h}$ decreases from 4.9 to $3.7 \mathrm{~nm}$ when the temperature rises from 15 to $24^{\circ} \mathrm{C}\left(T_{m}\right)$ and then progressively increases up to a plateau value of $6.2 \mathrm{~nm}$ at temperatures above $30^{\circ} \mathrm{C}$. The d-bicelles exhibited the same qualitative behavior, with $R_{h}$ values of $5.1,4.4$, and $7.0 \mathrm{~nm}$ at $15,20\left(T_{m}\right)$, and above $30^{\circ} \mathrm{C}$. These results clearly highlight that structural modifications occur above $T_{m}$, as previously reported in other studies ${ }^{34,36,39}$. Next, we explored by SANS the effect of the temperature on d-bicelle morphology in $42 \% \mathrm{~d}-\mathrm{TNE}$ at $22^{\circ} \mathrm{C}$, two degrees above the gel-to-fluid transition temperature, and at $37^{\circ} \mathrm{C}$, which is the physiological temperature (Figure 4B). In correlation with our DLS data, the morphology of dbicelles is clearly modified with temperature. Not surprisingly, this change occurs close to $T_{m}$. At $22^{\circ} \mathrm{C}$, good fits were obtained with the "core-shell cylinder" model with a radius $(R)$ of $42 \AA$ and a thickness $(t)$ of $40 \AA$ (Figure 4B) and we can conclude that disk-shaped objects remain present at least two degrees above $T_{m}$. On the other hand, no suitable fits with the same parameters were obtained for data acquired at $37^{\circ} \mathrm{C}$. Instead, at $37^{\circ} \mathrm{C}$, good fits were obtained by keeping the same model but by changing the initial parameters and unfixing the thickness of the core in order to design an elongated cylinder (Figure 4B). The calculated values for the cylinder were $26 \AA$ for the total radius $(R)$ and $192 \AA$ in thickness $(t)$. The same observations were done for the $h$ bicelles (data not shown). We conclude that elongated mixed-micelles do appear at this temperature, as reported in previous studies ${ }^{36,43}$.

As shown in Figure 4B, the SANS signal observed for the d-bicelles in $100 \%$ d-TNE is at least two orders of magnitude lower than that in $42 \%$ TNE. Thus, despite the change in morphology, deduced from data of d-bicelles in $42 \% \mathrm{~d}$-TNE, we conclude that full contrast-matching is obtained for d-bicelles in $100 \% \mathrm{~d}-\mathrm{TNE}$. 
To sum up, whatever the form adopted by the bicelles, we show that they can be contrastmatched. This novel approach may be designed to specifically probe the SANS signal of a protein in interaction with membrane lipids. The morphological modifications should, however, be considered for any further investigations, particularly if one wants to use molecular dynamics simulations to model the entire protein/bicelle complex.

Experimental application: DYS-R11-15 in interaction with d-bicelles

To experimentally validate this approach and to specifically probe the signal coming from a protein bound to membrane lipids, we applied the method to a protein-lipid complex. This complex is made of an amphipathic peripheral protein bound to a bicelle. For the protein part, we used a protein fragment belonging to the dystrophin central domain DYS R11-15 (from the $11^{\text {th }}$ to the $15^{\text {th }}$ spectrin-like repeats) for which both stability alone in solution and strong interaction with lipids have been thoroughly described ${ }^{45-47}$. Although the three-dimensional structure of R11-15 alone is not accessible by NMR and XRC due to its size (60 kDa) and its flexibility, an all-atom model was recently proposed by coupling SAXS and molecular modeling ${ }^{74}$. For the bicellar part of the complex, we used DHPC/DMPC h-bicelles $\left(q_{\text {eff }}=1.3,50 \mathrm{mM}\right)$. We examined the interaction of the protein with the h-bicelles, in the same experimental conditions as for further SANS analysis, by performing intrinsic tryptophan fluorescence measurements and chromatographic co-elution (Figure S3B and S3C). Then, we analyzed the DYS R11-15 protein alone or in interaction with the d-bicelles by SANS (Figure 5). We used exactly the same buffer and the same batch of bicelles in the samples of bicelles alone and DYS R11-15/bicelle complexes. Data were recorded at $93 \mu \mathrm{M}(5.6 \mathrm{~g} / \mathrm{L})$ of DYS R11-15 in 100\% d-TNE buffer at $18^{\circ} \mathrm{C}$. The specific SANS data were obtained following buffer or d-bicelles signal subtraction for the protein alone or in the presence of d-bicelles, respectively, and after incoherent background 
subtraction. In experiments designed to probe three-dimensional modifications of peripheral proteins bound to lipids, it is fundamental to avoid any signal coming from the peripheral proteins alone in solution. Within the concentrations used in our experiments presented in Figure 5 , each protein in solution is bound to at least one bicelle, as concluded from chromatographic co-elution (Figure S3C). SANS raw data of the dystrophin in absence and presence of bicelles are perfectly superimposed, as shown in the insert on Figure 5. From the Guinier approximation, the radii of gyration are $56.2 \pm 0.8$ and $55.9 \pm 0.8 \AA$ for the protein alone and for the protein in the presence of contrast-matched d-bicelles, respectively. In the case of large conformational changes due to lipid binding, $R_{g}$ would have been affected and the scattering curves would be different. Under the conditions of this experiment, we conclude that the native tertiary structure of the protein is maintained when bound to bicelles or that no conformational modification is detectable by SANS. A study of conformational modification of dystrophin fragments bound to bicelles in other conditions is beyond the scope of the present paper. To determine whether the method would be suitable for experiments requiring higher amounts of bicelles, in additional experiments, more concentrated samples of d-bicelles alone were also analyzed. We observed that their residual signal remains negligible (Figure S1). According to the IBM and using a CBC of $6 \mathrm{mM}$, bicelles with $q_{\text {eff }}=1.3$ at $50 \mathrm{mM}, q_{\text {eff }}=1.1$ at $100 \mathrm{mM}$, and $q_{\text {eff }}=1$ at $225 \mathrm{mM}$ of lipids correspond approximately to 130,350 , and $920 \mu \mathrm{M}$ of bicellar objects, respectively. These concentrations of bicellar objects seem large enough to ensure that all proteins are bound to at least one contrast-matched bicelle in the classical protein concentration range used in SANS (5$10 \mathrm{~g} / \mathrm{L})$

Going further in bicelle analysis: bicelles in HPSEC-SANS 
All the SANS data presented above were acquired in a standard sample environment (Hellma cell) since the DYS-R11-15 is a quite stable protein. Some less stable membrane proteins tend to form aggregates that would dramatically affect the SANS signal. To overcome this, we attempted to explore the behavior of bicelles in a size exclusion chromatography system, with the aim of targeting the SANS acquisition on the appropriate membrane mimic system, either alone or putatively in interaction with a partner. The results in Figure 6 show that the DMPC/DHPC h-bicelles are compatible with an on-line HPLC system such as the one available on $\mathrm{D} 22^{58}$ (ILL, Grenoble) since they are eluted as a single peak. The elution of bicelles can be followed thank to their absorbance at $210 \mathrm{~nm}$ and does not need the incorporation of a probe as previously described with LC experiments performed on DMPC/DPC (dodecylphosphocholine) bicelles $^{18}$ (the new ILL-D22 SEC-SANS set up enables to record absorbance at up to 4 different wavelengths). Interestingly, SANS data acquired on samples from the top of the elution peak were perfectly fitted with the "core-shell cylinder" model ${ }^{64}$, highlighting that bicelles maintain their disk-shaped conformation after travelling through the HPSEC column. We could not analyze the d-bicelles in the same way because of the prohibitive cost of the d-DHPCsupplemented elution buffer. Using h-DHPC instead does not allow the d-bicelles to remain contrast-matched due to the rapid exchange between the d-DHPC from the bicelle rim and the free h-DHPC present in the buffer (data not shown). Nevertheless, supplementing the buffer with d-DHPC should allow the d-bicelles to remain contrast-matched throughout an HPSEC-SANS measurement. Thus, this system could be applied to the characterization of other peripheral proteins and even integral membrane proteins in a bicellar environment, as previously done in NMR and XRC.

CONCLUSION 
In the present paper, we show that isotropic hydrogenated and deuterated bicelles can be characterized by SANS and finely controlled in size for biological applications. We demonstrate that the isotropic d-bicelles can be contrast-matched in SANS experiments using a $100 \% \mathrm{D}_{2} \mathrm{O}$ based buffer at physiological $\mathrm{pH}$ and salt concentrations. Moreover, we highlight that the signal coming from a peripheral protein bound to the d-bicelles can be separately and specifically probed by SANS. As a reminder, deuterated phospholipids used in the present study are commercially available enabling an easy preparation of d-bicelles with a determined size. Thereby, our method may represent an advantage compared to the deuterated nanodiscs, for which MSP purification in deuterated form might be tricky. These contrast-matched d-bicelles give rise to a wide range of biological applications to separately and specifically probe the solution structure of peripheral proteins and even fully integral membrane proteins in interaction with membrane lipids.

\section{ASSOCIATED CONTENT}

SANS data of h- and d-bicelles at several concentrations; SDS-PAGE analysis of DYS R11-15, tryptophan fluorescence spectra of the protein with or without h-bicelles and chromatographic co-elution analysis. This material is available free of charge via the Internet at http://pubs.acs.org.

\section{AUTHOR INFORMATION}

Corresponding Author

*E-mail: sophie.combet@cea.fr

\section{Notes}


The authors declare no competing financial interest. Schemes of the proteins in the graphical abstract were drawn from MyDomains - Image Creator. The bicelle models were generated by molecular modeling ${ }^{75,76}$.

\section{ACKNOWLEDGMENT}

The authors thank the Association Française contre les Myopathies-Telethon, the Conseil Régional de Bretagne, the Laboratoire Léon-Brillouin (LLB, Saclay, France), and the Synchrotron SOLEIL (Saint-Aubin, France) for funding this project. The Laboratoire LéonBrillouin, the Jülich Centre for Neutron Science (JCNS) at the Heinz Maier-Leibnitz Zentrum (MLZ, Garching, Germany), and the Institut Laue-Langevin (ILL, Grenoble, France) neutron facilities are acknowledged for beamtime allocation and support on, respectively, PACE, KWS1, and D22 SANS instruments. SANS experiments at JCNS-MLZ have been supported by the European Commission under the 7th Framework Programme through the "Research Infrastructures" action of the "Capacities" Programme, NMI3-II Grant number 283883. The authors acknowledge, at the University of Rennes 1, the Centre de Purification des Protéines of the UMR-CNRS 6290, the PRISM platform for NMR facilities, and BIOSIT for spectrofluorimetry facilities. The authors are also grateful to Giulio Gambarota (Université de Rennes 1) for his reading of the manuscript.

\section{REFERENCES}

(1) Fagerberg, L.; Jonasson, K.; von Heijne, G.; Uhlén, M.; Berglund, L. Prediction of the Human Membrane Proteome. Proteomics 2010, 10 (6), 1141-1149.

(2) Membrane Proteins of Known Structure http://blanco.biomol.uci.edu/mpstruc/

(3) Seddon, A. M.; Curnow, P.; Booth, P. J. Membrane Proteins, Lipids and Detergents: Not Just a Soap Opera. Biochim. Biophvs. Acta 2004, 1666 (1-2), 105-117.

(4) Petoukhov, M. V.; Svergun, D. I. Analysis of X-Ray and Neutron Scattering from Biomacromolecular Solutions. Curr. Opin. Struct. Biol. 2007, 17 (5), 562-571.

(5) Bizien, T.; Durand, D.; Roblina, P.; Thureau, A.; Vachette, P.; Pérez, J. A Brief Survey of State-of-the-Art BioSAXS. Protein Pept. Lett. 2016, 23 (3), 217-231. 
(6) Heller, W. T. Small-Angle Neutron Scattering and Contrast Variation: A Powerful Combination for Studying Biological Structures. Acta Crvstallogr. Sect.D 2010, 66 (11), 1213-1217.

(7) Breyton, C.; Gabel, F.; Lethier, M.; Flayhan, A.; Durand, G.; Jault, J.-M.; Juillan-Binard, C.; Imbert, L.; Moulin, M.; Ravaud, S.; et al. Small Angle Neutron Scattering for the Study of Solubilised Membrane Proteins. Eur. Phvs.J.E. Soft Matter 2013, 36 (7), 71.

(8) Gabel, F.; Lensink, M. F.; Clantin, B.; Jacob-Dubuisson, F.; Villeret, V.; Ebel, C. Probing the Conformation of FhaC with Small-Angle Neutron Scattering and Molecular Modeling. Biophvs.J. 2014, 107 (1), 185-196.

(9) Frey, L.; Lakomek, N.-A.; Riek, R.; Bibow, S. Micelles, Bicelles, and Nanodiscs:

Comparing the Impact of Membrane Mimetics on Membrane Protein Backbone Dynamics. Angew. Chem. Int. Ed Engl. 2017, 56 (1), 380-383.

(10) Dörr, J. M.; Scheidelaar, S.; Koorengevel, M. C.; Dominguez, J. J.; Schäfer, M.; van Walree, C. A.; Killian, J. A. The Styrene-Maleic Acid Copolymer: A Versatile Tool in Membrane Research. Eur. Biophvs. J.EBJ 2016, 45 (1), 3-21.

(11) Vestergaard, M.; Kraft, J. F.; Vosegaard, T.; Thøgersen, L.; Schiøtt, B. Bicelles and Other Membrane Mimics: Comparison of Structure, Properties, and Dynamics from MD Simulations. L. Phvs. Chem. B 2015, 119 (52), 15831-15843.

(12) Warschawski, D. E.; Arnold, A. A.; Beaugrand, M.; Gravel, A.; Chartrand, É.; Marcotte, I. Choosing Membrane Mimetics for NMR Structural Studies of Transmembrane Proteins. Biochim. Bionhvs. Acta 2011, 1808 (8), 1957-1974.

(13) Bayburt, T. H.; Grinkova, Y. V.; Sligar, S. G. Self-Assembly of Discoidal Phospholipid Bilayer Nanoparticles with Membrane Scaffold Proteins. Nano Lett. 2002, 2 (8), 853-856.

(14) Knowles, T. J.; Finka, R.; Smith, C.; Lin, Y.-P.; Dafforn, T.; Overduin, M. Membrane Proteins Solubilized Intact in Lipid Containing Nanoparticles Bounded by Styrene Maleic Acid Copolymer. L.Am. Chem.Soc. 2009, 131 (22), 7484-7485.

(15) Maric, S.; Skar-Gislinge, N.; Midtgaard, S.; Thygesen, M. B.; Schiller, J.; Frielinghaus, H.; Moulin, M.; Haertlein, M.; Forsyth, V. T.; Pomorski, T. G.; et al. Stealth Carriers for Low-Resolution Structure Determination of Membrane Proteins in Solution. Acta Crvstallogr. D Biol. Crvstallogr. 2014, 70 (Pt 2), 317-328.

(16) Wang, X.; Mu, Z.; Li, Y.; Bi, Y.; Wang, Y. Smaller Nanodiscs Are Suitable for Studying Protein Lipid Interactions by Solution NMR. Protein J. 2015, 34 (3), 205-211.

(17) Grinkova, Y. V.; Denisov, I. G.; Sligar, S. G. Engineering Extended Membrane Scaffold Proteins for Self-Assembly of Soluble Nanoscale Lipid Bilayers. Protein Eng. Des. Sel. PEDS 2010, 23 (11), 843-848.

(18) Draney, A. W.; Smrt, S. T.; Lorieau, J. L. Use of Isotropically Tumbling Bicelles to Measure Curvature Induced by Membrane Components. Langmuir ACS J.Surf. Colloids 2014, 30 (39), 11723-11733.

(19) Zimmerberg, J.; Kozlov, M. M. How Proteins Produce Cellular Membrane Curvature. Nat. Rev. Mol. Cell Biol. 2006, 7 (1), 9-19.

(20) Mazer, N. A.; Benedek, G. B.; Carey, M. C. Quasielastic Light-Scattering Studies of Aqueous Biliary Lipid Systems. Mixed Micelle Formation in Bile Salt-Lecithin Solutions. Biochemistrv (Mosc.) 1980, 19 (4), 601-615.

(21) Sanders, C. R.; Prestegard, J. H. Magnetically Orientable Phospholipid Bilayers Containing Small Amounts of a Bile Salt Analogue, CHAPSO. Bionhvs.J. 1990, 58 (2), $447-460$. 
(22) Bian, J.; Roberts, M. F. Phase Separation in Short-Chain Lecithin/Gel-State Long Chain Lecithin Aggregates. Biochemistrv (Mosc.) 1990, 29 (34), 7928-7935.

(23) Lin, T. L.; Liu, C. C.; Roberts, M. F.; Chen, S. H. Structure of Mixed Short-Chain Lecithin/Long-Chain Lecithin Aggregates Studied by Small-Angle Neutron Scattering. $L$ Phvs. Chem. 1991, 95 (15), 6020-6027.

(24) Minto, R. E.; Adhikari, P. R.; Lorigan, G. A. A 2H Solid-State NMR Spectroscopic Investigation of Biomimetic Bicelles Containing Cholesterol and Polyunsaturated Phosphatidylcholine. Chem. Phvs. Lipids 2004, 132 (1), 55-64.

(25) Triba, M. N.; Devaux, P. F.; Warschawski, D. E. Effects of Lipid Chain Length and Unsaturation on Bicelles Stability. A Phosphorus NMR Study. Biophys. J. 2006, 91 (4), 1357-1367.

(26) Struppe, J.; Whiles, J. A.; Vold, R. R. Acidic Phospholipid Bicelles: A Versatile Model Membrane System. Biophys. J. 2000, 78 (1), 281-289.

(27) Liebau, J.; Pettersson, P.; Zuber, P.; Ariöz, C.; Mäler, L. Fast-Tumbling Bicelles Constructed from Native Escherichia Coli Lipids. Biochim. Biophvs. Acta 2016, 1858 (9), 2097-2105.

(28) Sanders, C. R.; Schwonek, J. P. Characterization of Magnetically Orientable Bilayers in Mixtures of Dihexanoylphosphatidylcholine and Dimyristoylphosphatidylcholine by Solid-State NMR. Biochemistrv (Mosc.) 1992, 31 (37), 8898-8905.

(29) Dürr, U. H. N.; Gildenberg, M.; Ramamoorthy, A. The Magic of Bicelles Lights up Membrane Protein Structure. Chem.Rev. 2012, 112 (11), 6054-6074.

(30) Dürr, U. H. N.; Soong, R.; Ramamoorthy, A. When Detergent Meets Bilayer: Birth and Coming of Age of Lipid Bicelles. Prog. Nucl. Magn. Reson. Spectrosc. 2013, 69, 1-22.

(31) Poulos, S.; Morgan, J. L. W.; Zimmer, J.; Faham, S. Bicelles Coming of Age: An Empirical Approach to Bicelle Crystallization. Methods Enzvmol. 2015, 557, 393-416.

(32) Ujwal, R.; Bowie, J. U. Crystallizing Membrane Proteins Using Lipidic Bicelles. Methods San Diego Calif 2011, 55 (4), 337-341.

(33) Ujwal, R.; Abramson, J. High-Throughput Crystallization of Membrane Proteins Using the Lipidic Bicelle Method. J. Vis. Exp. JoVE 2012, No. 59, e3383.

(34) van Dam, L.; Karlsson, G.; Edwards, K. Morphology of Magnetically Aligning DMPC/DHPC Aggregates-Perforated Sheets, Not Disks. Langmuir ACS J. Surf. Colloids 2006, 22 (7), 3280-3285.

(35) Glover, K. J.; Whiles, J. A.; Wu, G.; Yu, N.; Deems, R.; Struppe, J. O.; Stark, R. E.; Komives, E. A.; Vold, R. R. Structural Evaluation of Phospholipid Bicelles for SolutionState Studies of Membrane-Associated Biomolecules. Biophvs. J. 2001, 81 (4), 21632171.

(36) van Dam, L.; Karlsson, G.; Edwards, K. Direct Observation and Characterization of DMPC/DHPC Aggregates under Conditions Relevant for Biological Solution NMR. Biochim. Biophvs. Acta 2004, 1664 (2), 241-256.

(37) Beaugrand, M.; Arnold, A. A.; Hénin, J.; Warschawski, D. E.; Williamson, P. T. F.; Marcotte, I. Lipid Concentration and Molar Ratio Boundaries for the Use of Isotropic Bicelles. Langmuir ACS J.Surf. Colloids 2014, 30 (21), 6162-6170.

(38) Mineev, K. S.; Nadezhdin, K. D.; Goncharuk, S. A.; Arseniev, A. S. Characterization of Small Isotropic Bicelles with Various Compositions. Langmuir ACS J. Surf. Colloids 2016. 
(39) Ye, W.; Lind, J.; Eriksson, J.; Mäler, L. Characterization of the Morphology of FastTumbling Bicelles with Varying Composition. Lanomuir ACS J.Surf Colloids 2014, 30 (19), 5488-5496.

(40) Luchette, P. A.; Vetman, T. N.; Prosser, R. S.; Hancock, R. E.; Nieh, M. P.; Glinka, C. J.; Krueger, S.; Katsaras, J. Morphology of Fast-Tumbling Bicelles: A Small Angle Neutron Scattering and NMR Study. Biochim. Biophys. Acta 2001, 1513 (2), 83-94.

(41) Nieh, M.-P.; Glinka, C. J.; Krueger, S.; Prosser, R. S.; Katsaras, J. SANS Study on the Effect of Lanthanide Ions and Charged Lipids on the Morphology of Phospholipid Mixtures. Small-Angle Neutron Scattering. Biophys. J. 2002, 82 (5), 2487-2498.

(42) Nieh, M.-P.; Raghunathan, V. A.; Glinka, C. J.; Harroun, T. A.; Pabst, G.; Katsaras, J. Magnetically Alignable Phase of Phospholipid "Bicelle" Mixtures Is a Chiral Nematic Made Up of Wormlike Micelles. Langmuir 2004, 20 (19), 7893-7897.

(43) Li, M.; Morales, H. H.; Katsaras, J.; Kučerka, N.; Yang, Y.; Macdonald, P. M.; Nieh, M.P. Morphological Characterization of DMPC/CHAPSO Bicellar Mixtures: A Combined SANS and NMR Study. Lanomuir ACS J.Surf. Colloids 2013, 29 (51), 15943-15957.

(44) Nieh, M.-P.; Raghunathan, V. A.; Pabst, G.; Harroun, T.; Nagashima, K.; Morales, H.; Katsaras, J.; Macdonald, P. Temperature Driven Annealing of Perforations in Bicellar Model Membranes. Langmuir ACS J. Surf. Colloids 2011, 27 (8), 4838-4847.

(45) Legardinier, S.; Raguénès-Nicol, C.; Tascon, C.; Rocher, C.; Hardy, S.; Hubert, J.-F.; Le Rumeur, E. Mapping of the Lipid-Binding and Stability Properties of the Central Rod Domain of Human Dystrophin. L. Mol. Biol. 2009, 389 (3), 546-558.

(46) Sarkis, J.; Hubert, J.-F.; Legrand, B.; Robert, E.; Chéron, A.; Jardin, J.; Hitti, E.; Le Rumeur, E.; Vié, V. Spectrin-like Repeats 11-15 of Human Dystrophin Show Adaptations to a Lipidic Environment. L.Biol. Chem. 2011, 286 (35), 30481-30491.

(47) Sarkis, J.; Vié, V.; Winder, S. J.; Renault, A.; Le Rumeur, E.; Hubert, J.-F. Resisting Sarcolemmal Rupture: Dystrophin Repeats Increase Membrane-Actin Stiffness. FASEB J. Off. Publ. Fed. Am. Soc. Exp. Biol. 2013, 27 (1), 359-367.

(48) Vold, R. R.; Prosser, R. S. Magnetically Oriented Phospholipid Bilayered Micelles for Structural Studies of Polypeptides. Does the Ideal Bicelle Exist? J. Magn. Reson. B 1996, $113(3), 267-271$.

(49) Triba, M. N.; Warschawski, D. E.; Devaux, P. F. Reinvestigation by Phosphorus NMR of Lipid Distribution in Bicelles. Biophvs. J. 2005, 88 (3), 1887-1901.

(50) Petrache, H. I.; Tristram-Nagle, S.; Gawrisch, K.; Harries, D.; Parsegian, V. A.; Nagle, J. F. Structure and Fluctuations of Charged Phosphatidylserine Bilayers in the Absence of Salt. Biophys.J. 2004, 86 (3), 1574-1586.

(51) Träuble, H.; Haynes, D. H. The Volume Change in Lipid Bilayer Lamellae at the Crystalline-Liquid Crystalline Phase Transition. Chem. Phys.Lipids 1971, 7 (4), 324-335.

(53) Cho, C. H.; Urquidi, J.; Singh, S.; Robinson, G. W. Thermal Offset Viscosities of Liquid H2O, D2O, and T2O. L. Phvs. Chem. B 1999, 103 (11), 1991-1994.

(54) Auvray, L.; Lairez, D. Small Angle Neutron Scattering facility PACE http://wwwllb.cea.fr/spectros/pdf/pace-llb.pdf

(55) Feoktystov, A. V.; Frielinghaus, H.; Di, Z.; Jaksch, S.; Pipich, V.; Appavou, M.-S.; Babcock, E.; Hanslik, R.; Engels, R.; Kemmerling, G.; et al. KWS-1 High-Resolution 
Small-Angle Neutron Scattering Instrument at JCNS: Current State. L Appl. Crvstallogr. 2015, 48 (1), 61-70.

(56) Frielinghaus, H.; Feoktystov, A.; Berts, I.; Mangiapia, G. KWS-1: Small-Angle Scattering Diffractometer. J. Large-Scale Res. Facil. JLSRF 2015, 1.

(57) Instrument layout (D22) https://www.ill.eu/instruments-support/instrumentsgroups/instruments/d22/description/instrument-layout/

(58) Jordan, A.; Jacques, M.; Merrick, C.; Devos, J.; Forsyth, V. T.; Porcar, L.; Martel, A. SEC-SANS: Size Exclusion Chromatography Combined in Situ with Small-Angle Neutron Scattering. LAspol. Crvstallogr. 2016, 49 (6), 2015-2020.

(59) Petoukhov, M. V.; Franke, D.; Shkumatov, A. V.; Tria, G.; Kikhney, A. G.; Gajda, M.; Gorba, C.; Mertens, H. D. T.; Konarev, P. V.; Svergun, D. I. New Developments in the ATSAS Program Package for Small-Angle Scattering Data Analysis. L_Anpl. Crvstallogr. 2012, 45 (2), 342-350.

(60) Konarev, P. V.; Volkov, V. V.; Sokolova, A. V.; Koch, M. H. J.; Svergun, D. I. PRIMUS : A Windows PC-Based System for Small-Angle Scattering Data Analysis. L.Apol. Crvstallogr. 2003, 36 (5), 1277-1282.

(61) Glatter, O.; Kratky, O. Small Angle X-Ray Scattering; Academic Press, 1982.

(62) Tanford, C. The Hydrophobic Effect: Formation of Micelles and Biological Membranes; Wiley, 1980.

(59) Neutron Activation Calculator https:/www.ncnr.nist.gov/resources/activation/

(64) Kline, S. R. Reduction and Analysis of SANS and USANS Data Using IGOR Pro. J. Appl. Crustallogr. 2006, 39 (6), 895-900.

(60) SasView http://www.sasview.org/

(66) Chou, J. J.; Baber, J. L.; Bax, A. Characterization of Phospholipid Mixed Micelles by Translational Diffusion. L.Biomol. NMR 2004, 29 (3), 299-308.

(67) Glover, K. J.; Whiles, J. A.; Vold, R. R.; Melacini, G. Position of Residues in Transmembrane Peptides with Respect to the Lipid Bilayer: A Combined Lipid Noes and Water Chemical Exchange Approach in Phospholipid Bicelles. L_Biomol. NMR 2002, 22 (1), 57-64.

(68) Nagle, J. F.; Wilkinson, D. A. Lecithin Bilayers. Density Measurement and Molecular Interactions. Biophvs. J. 1978, 23 (2), 159-175.

(69) Tristram-Nagle, S.; Liu, Y.; Legleiter, J.; Nagle, J. F. Structure of Gel Phase DMPC Determined by X-Ray Diffraction. Biophvs.J. 2002, 83 (6), 3324-3335.

(70) Kučerka, N.; Liu, Y.; Chu, N.; Petrache, H. I.; Tristram-Nagle, S.; Nagle, J. F. Structure of Fully Hydrated Fluid Phase DMPC and DLPC Lipid Bilayers Using X-Ray Scattering from Oriented Multilamellar Arrays and from Unilamellar Vesicles. Biophys. J. 2005, 88 (4), 2626-2637.

(71) Gabriel, N. E.; Roberts, M. F. Short-Chain Lecithin/Long-Chain Phospholipid Unilamellar Vesicles: Asymmetry, Dynamics, and Enzymatic Hydrolysis of the Short-Chain Component. Biochemistrv (Mosc.) 1987, 26 (9), 2432-2440.

(72) Guard-Friar, D.; Chen, C. H.; Engle, A. S. Deuterium Isotope Effect on the Stability of Molecules: Phospholipids. J.Phvs. Chem. 1985, 89 (9), 1810-1813.

(73) Wang, G. X.; Chen, C. H. Thermodynamic Elucidation of Structural Stability of Deuterated Biological Molecules: Deuterated Phospholipid Vesicles in H2O. Arch. Biochem. Biophys. 1993, 301 (2), 330-335. 
(74) Molza, A.-E.; Férey, N.; Czjzek, M.; Le Rumeur, E.; Hubert, J.-F.; Tek, A.; Laurent, B.; Baaden, M.; Delalande, O. Innovative Interactive Flexible Docking Method for MultiScale Reconstruction Elucidates Dystrophin Molecular Assembly. Earadav Discuss. 2014, 169, 45-62.

(75) Marrink, S. J.; Risselada, H. J.; Yefimov, S.; Tieleman, D. P.; de Vries, A. H. The MARTINI Force Field: Coarse Grained Model for Biomolecular Simulations. LLPhvs. Chem. B 2007, 111 (27), 7812-7824.

(76) Hess, B.; Kutzner, C.; van der Spoel, D.; Lindahl, E. GROMACS 4: Algorithms for Highly Efficient, Load-Balanced, and Scalable Molecular Simulation. J.Chem. Theorv Comput. 2008, 4 (3), 435-447. 
Insert Table of Contents Graphic and Synopsis Here

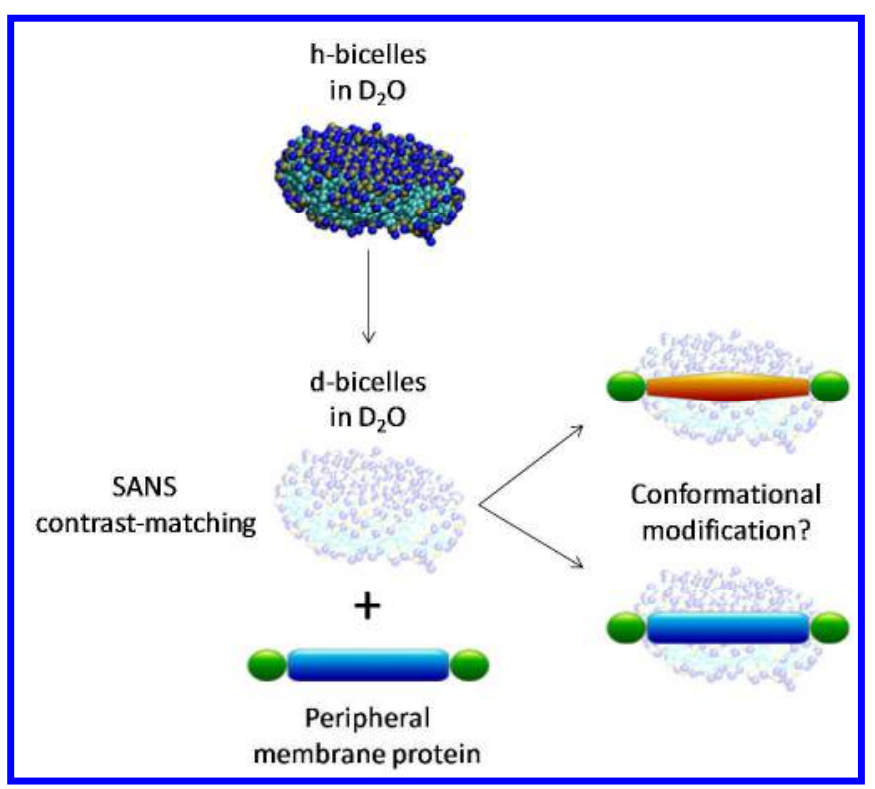

ACS Paragon Plus Environment 


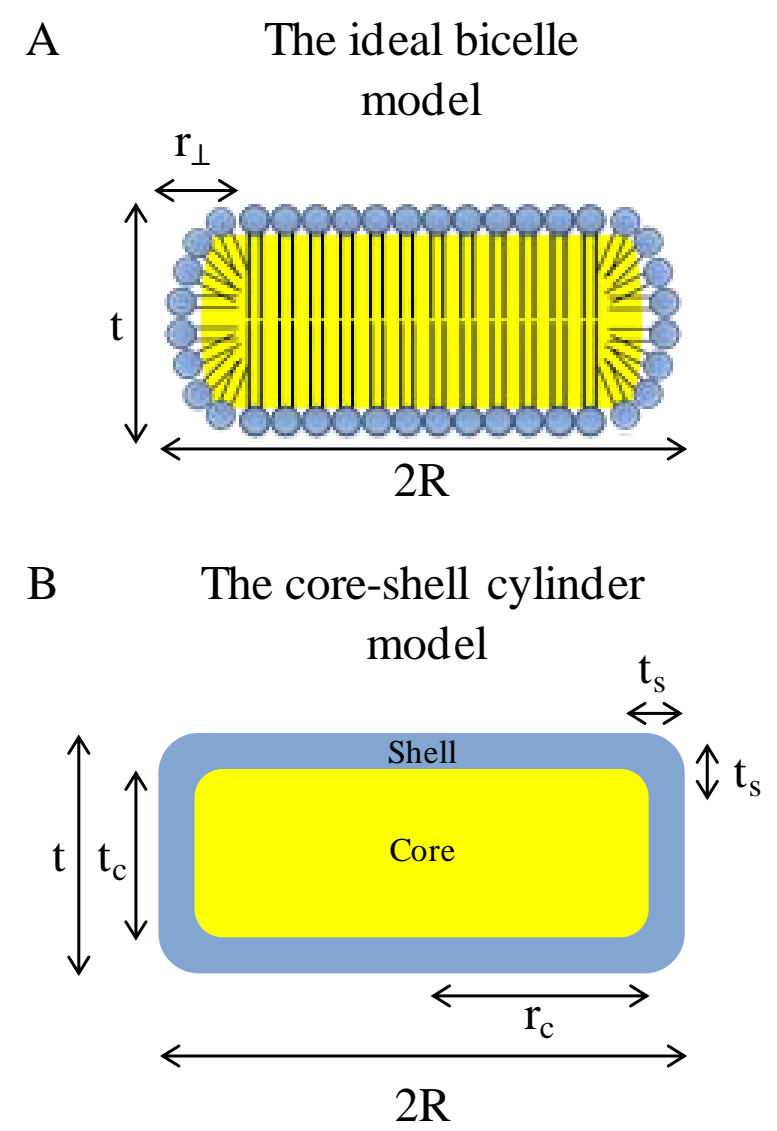

Figure 1: (A) Schematic representation of the ideal bicelle model. For DMPC/DHPC bicelles, $R$ is the radius of the bicelle, $r \perp$ is the thickness of the rim $(11 \AA$, the length of a DHPC molecule), and $t$ is the thickness of the DMPC bilayer (assumed to be $40 \AA$ ) ${ }^{49}$. (B) Schematic representation of the "core-shell cylinder" model, where $t_{c}$ is the thickness of the core, $r_{c}$ is the radius of the core, and $t_{s}$ is the thickness of the shell. As described in the materials and methods, the calculated scattering length densities of the core and of the shell are, respectively, -0.58 and $2.2410^{-6} \AA^{-1}$ for h-bicelles and 7.39 and $5.0510^{-6} \AA^{-1}$ for d-bicelles. 

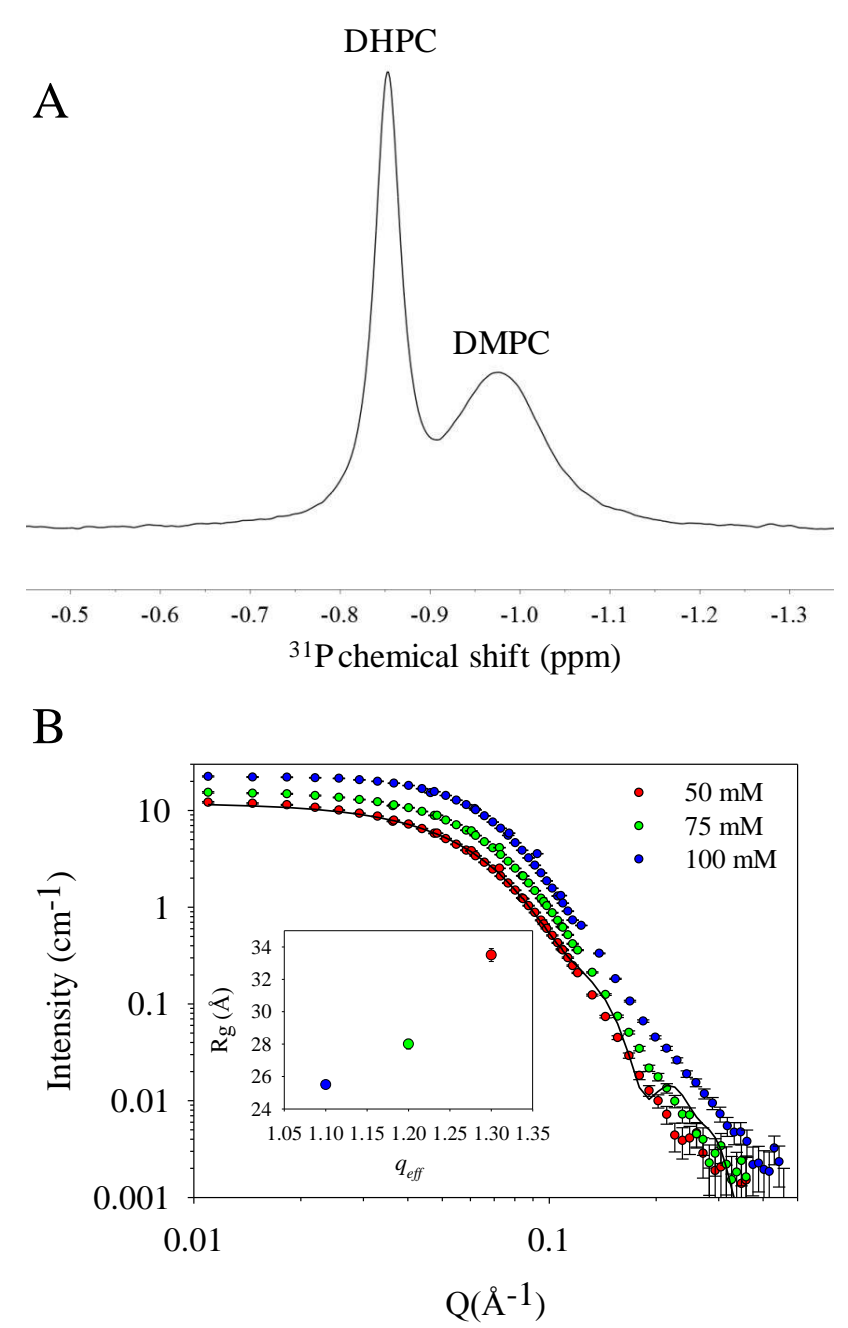

Figure 2: (A) ${ }^{31} \mathrm{P}$ NMR spectrum of $q=1$ h-bicelles at $200 \mathrm{mM}$, typical of a bicelle organization. (B) SANS intensities measured for $q=1 \mathrm{~h}$-bicelles at $20^{\circ} \mathrm{C}$ for a total DMPC/DHPC concentration of $100\left(q_{\text {eff }}=1.1\right)$ (blue), $75\left(q_{\text {eff }}=1.2\right)($ green$)$, and $50\left(q_{\text {eff }}=\right.$ 1.3) (red) $\mathrm{mM}$ in $100 \% \mathrm{D}_{2} \mathrm{O}$ d-TNE buffer. Data at $50 \mathrm{mM}$ were fitted (black line) with the "core-shell cylinder" model. The thickness $(t)$ is $40 \AA$ and the radius $(R)$ is $42 \AA$, in line with the dimensions of a disk. Insert: $R_{g}$ as a function of $q_{\text {eff }}$ showing the increased bicelle size with $q_{\text {eff. }}$ 


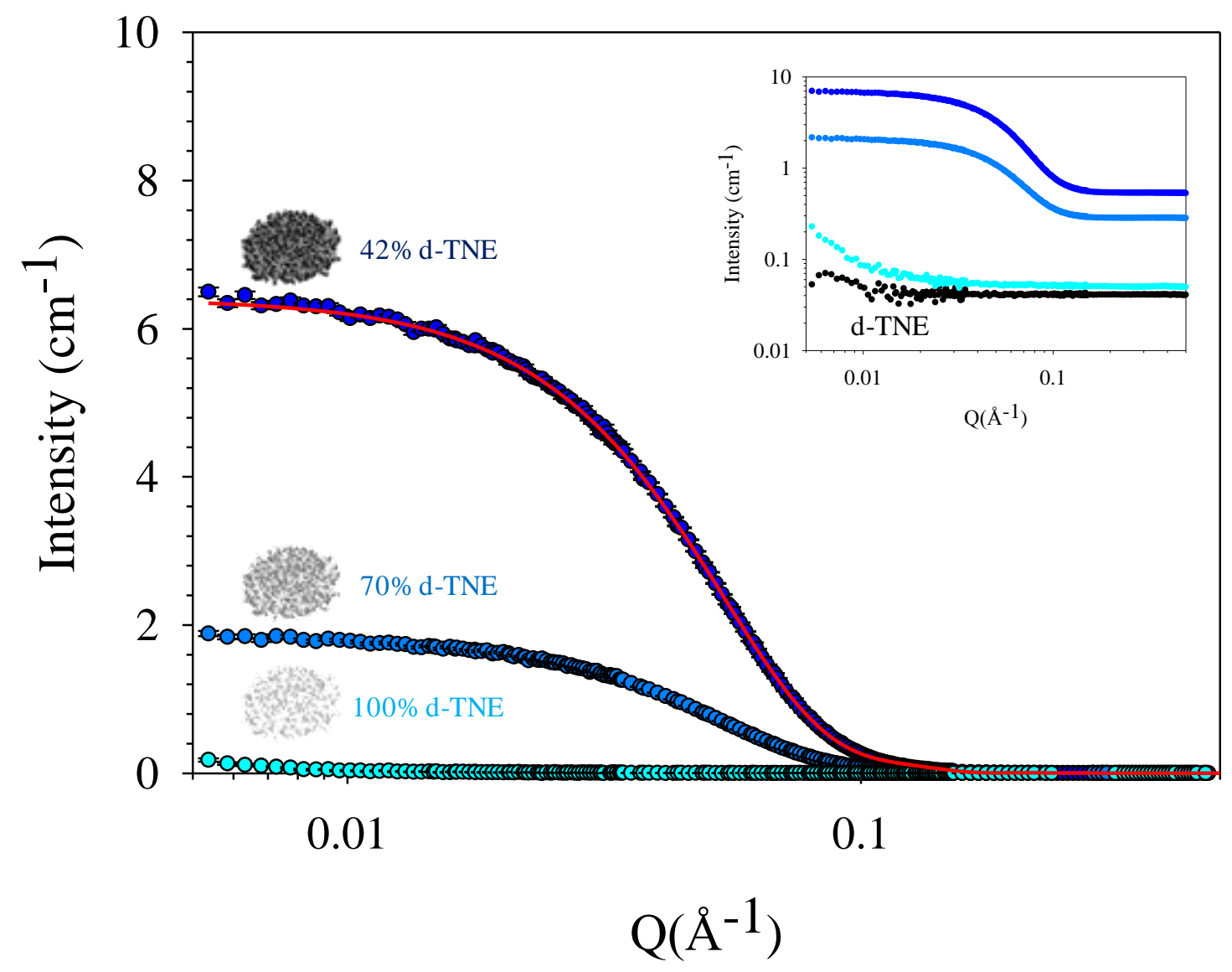

Figure 3: SANS intensities measured for $q_{\text {eff }}=1.3$ d-bicelles at $50 \mathrm{mM}$ lipids in $42 \%$ (dark blue), $70 \%$ (blue), and $100 \%$ (cyan) $\mathrm{D}_{2} \mathrm{O}$ in d-TNE buffer (black) at $20^{\circ} \mathrm{C}$. The d-bicelles in $42 \%$ d-TNE were fitted with the "core-shell cylinder" model (red line), giving 40 and $42 \AA$ for the thickness $(t)$ and the radius $(R)$, respectively. The incoherent SANS signal was subtracted. Insert: the same data, without incoherent subtraction in a log/log scale, highlighting the small residual signal of d-bicelles at very small $Q$-values and compared to dTNE buffer prepared in $100 \% \mathrm{D}_{2} \mathrm{O}$ (black). 
A

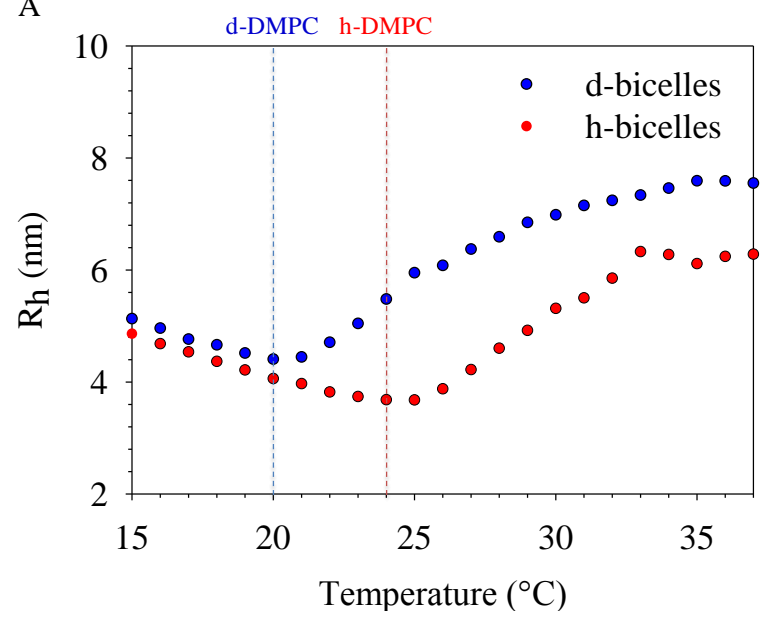

B

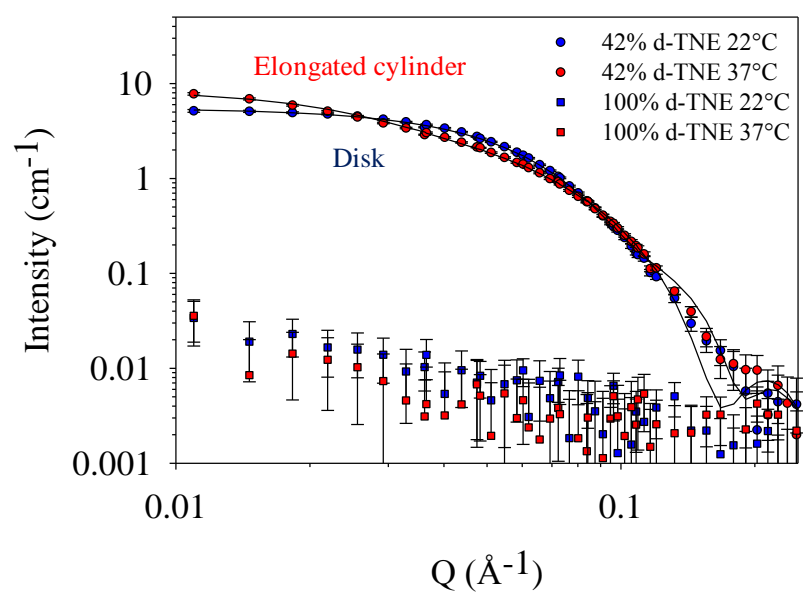

Figure 4: (A) DLS analysis of h- (red) and d-bicelles (blue) with $q_{\text {eff }}=1.3$ bicelles at $50 \mathrm{mM}$ from 15 to $37^{\circ} \mathrm{C}$ in d-TNE. Dotted lines indicate the temperature transition for $\mathrm{d}$ - and $\mathrm{h}$ DMPC (blue and red, respectively). (B) SANS intensities measured for $q_{\text {eff }}=1.3$ d-bicelles $(50 \mathrm{mM})$ at 22 (blue) and $37^{\circ} \mathrm{C}$ (red) in $42 \%$ (circles) and $100 \%$ (squares) d-TNE. The data were fitted (black lines) with the "core-shell cylinder" model. At $22^{\circ} \mathrm{C}$, the thickness $(t)$ is $40 \AA$ and the radius $(R)$ is $42.5 \AA$, in line with the dimensions of a disk, while at $37^{\circ} \mathrm{C}$, the radius is $26 \AA$ and the thickness is $192 \AA$, corresponding to an elongated cylinder. 


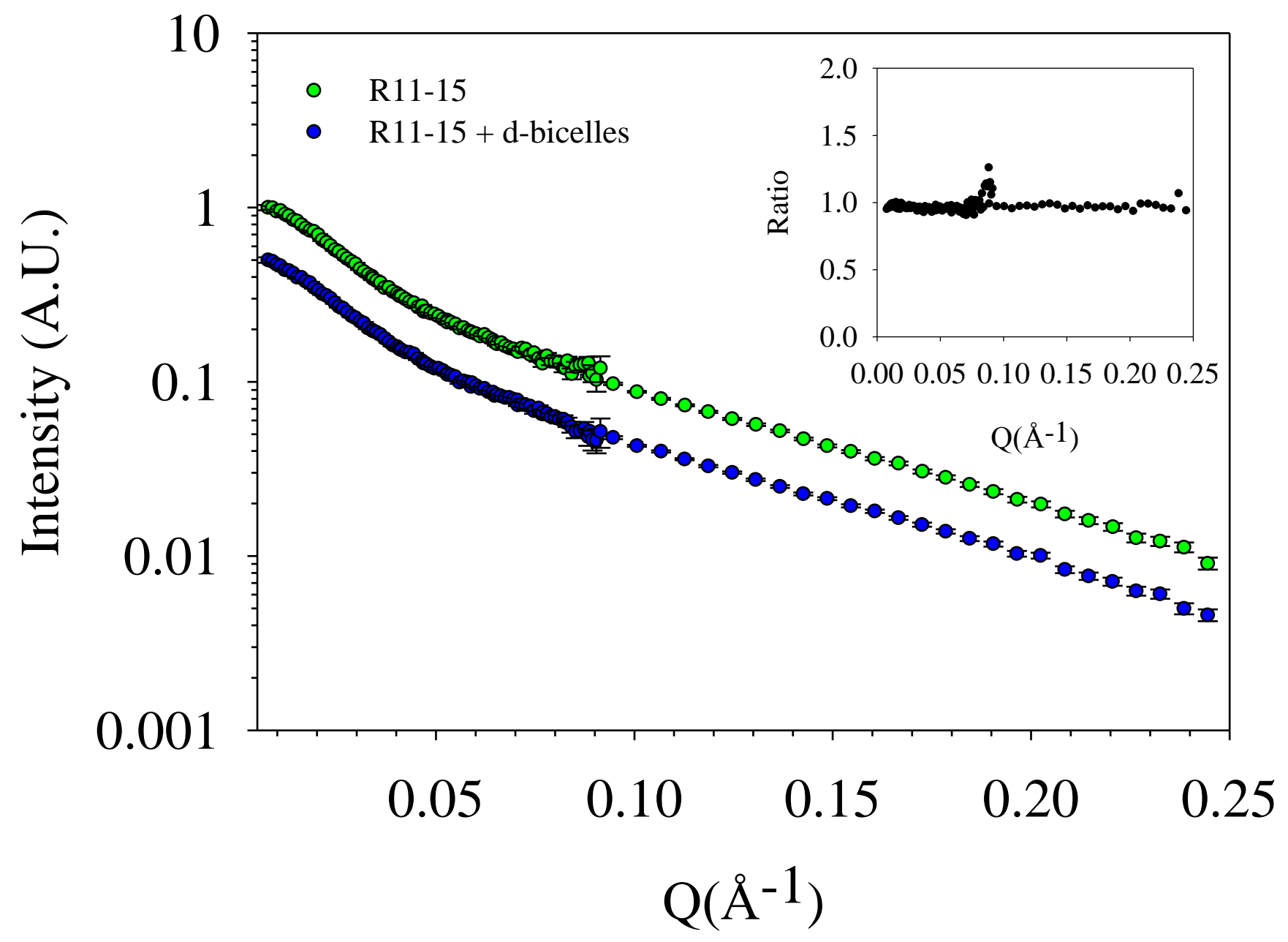

Figure 5: Normalized SANS intensities measured for DYS R11-15 at $93 \mu \mathrm{M}(5.6 \mathrm{~g} / \mathrm{L})$ alone (green) or in the presence of the d-bicelles (blue) in $100 \% \mathrm{D}_{2} \mathrm{O}$ d-TNE at $18^{\circ} \mathrm{C}$. Insert: the ratio of the two scattering curves. The blue curve is shifted for clarity since the two curves superimpose, as shown by the ratio of the raw data in the insert. 


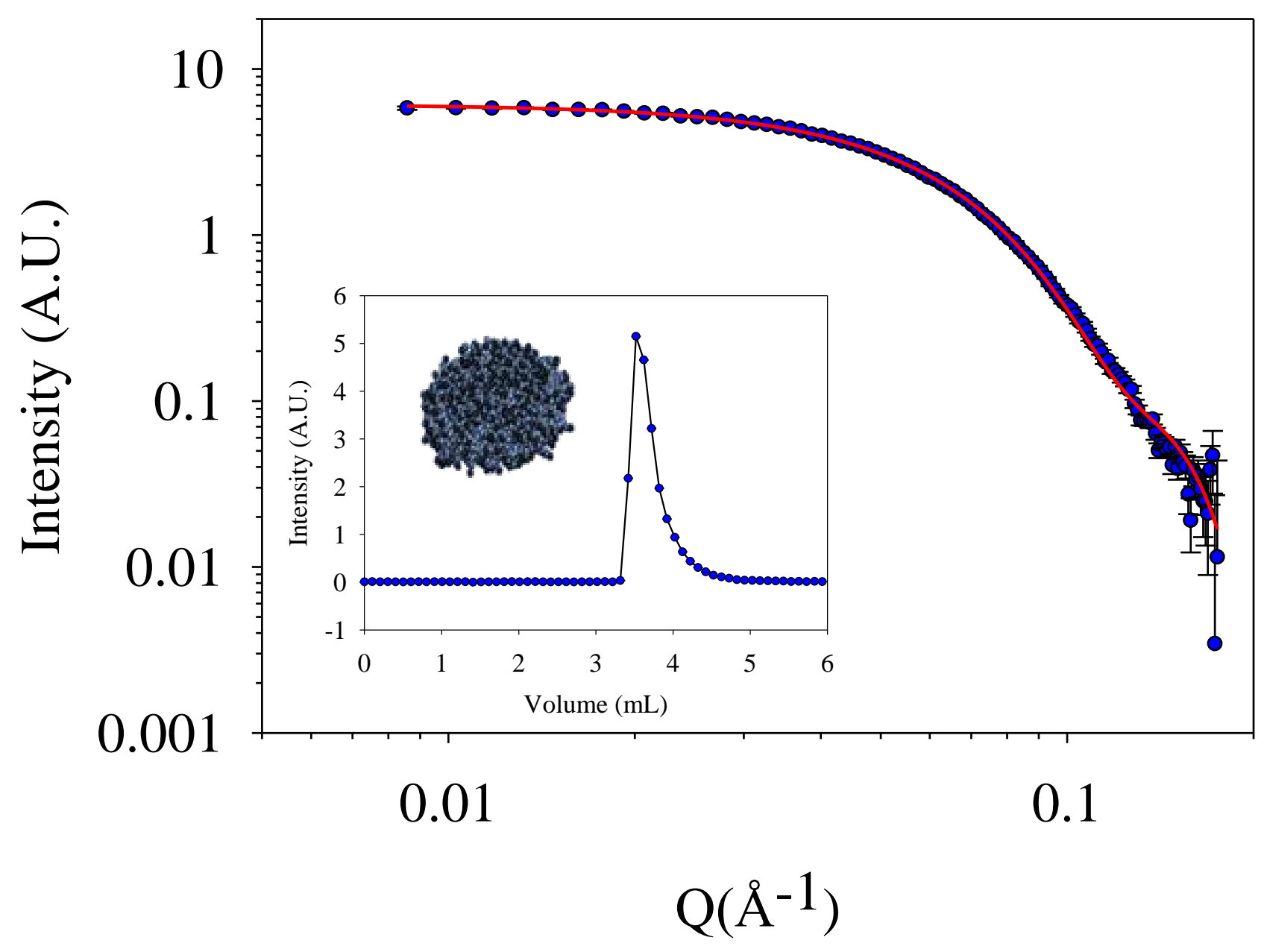

Figure 6: HPSEC-SANS intensities measured for h-bicelles fitted (red line) with the expected "core-shell cylinder" model as for the same sample in the Hellma cell environment. Insert: the associated scattergram (SANS detector) as a function of elution volume, showing one unique peak corresponding to h-bicelles. 